\title{
Kinetics of Inhibition of Xanthine Oxidase by Globularia alypum and its Protective Effect against Oxonate-Induced Hyperuricemia and Renal Dysfunction in Mice
}

\author{
Boussoualim Naouel, Trabsa hayat, Krache Iman, Arrar Lekhmissi, Baghiani Abderrahmane
}

Laboratory of biochemistry, SNV, University of SETIF 1. Algeria.

\begin{tabular}{l} 
ARTICLE INFO \\
\hline Article history: \\
Received on: 20/12/2015 \\
Revised on: 12/02/2016 \\
Accepted on: 03/03/2016 \\
Available online: $30 / 04 / 2016$ \\
\hline Key words: \\
Globularia alypum, \\
polyphenols, flavonoids, \\
Hyperuricemia, XO.
\end{tabular}

\section{INTRODUCTION}

Hyperuricemia is the most cited pathology involving $\mathrm{XO}$. It is a pathological state that arises from overproduction (by $\mathrm{XO}$ ) or under excretion (renal tubule disorders) of uric acid. As a result of hyperuricemia, insoluble uric acid forms microscopic crystals in the capillary vessels of joints. These crystals cause inflammation and sharp pain, which is termed acute gouty arthritis or acute gout (Sachs et al., 2009). Xanthine oxidase (XO) catalyses the oxidation of hypoxanthine and xanthine to uric acid. Therefore, $\mathrm{XO}$ inhibitors have been proposed as potential therapeutic agents for treating hyperuricemia as they could be used to block the biosynthesis of uric acid (Unno et al.,

* Corresponding Author

Boussoualim Naouel, Laboratory of biochemistry, SNV, University of SETIF 1. Algeria.Email: naouel_24@yahoo.fr
2004; Newcombe, 2013). Allopurinol is the most commonly used xanthine oxidase inhibitor prescribed clinically for the treatment of gout (Hille, 2010; Chen et al., 2011). However, the use of this agent is limited because of its undesirable effects (Bomalaski and Clark, 2004; Yu et al., 2006). Therefore, there is an urgent need to develop new XO inhibitors from natural sources.

The use of natural products isolated from medicinal plants represented a good source of novel and clinically important drugs in connection with the treatment of some kinds of clinical disorders as hyperuricemia and gout. A potential source of such compounds can be obtained from medicinal plants. Flavonoids and polyphenolic have been reported to possess xanthine oxidase inhibitory activity (Lin et al., 2002). As part of our efforts to find antihyperuricemic agents from herbs: Globularia alypum belongs to Globulariaceae commonly known as 'Tasalgha, It is widely distributed in the Mediterranean region. 
It is one of the most traditional plant remedies. The plant is known for its uses in the indigenous system of medicine for a variety of purposes such as hypoglycaemic agent, laxative, cholagogue, stomachic, purgative, sudorific and also in the treatment of cardio-vascular and renal diseases (Fehri and Aiache, 2010; Balansard and Delphant, 1948), rhumatism, gout, typhoid, intermittent fever and diabetes (Skim et al., 1999; Jouad et al., 2002).

The aim of this study was to evaluate the in vitro inhibition of xanthine oxidase as well as the in vivo hypourecimic effect of GA extracts in mice.

\section{MATERIALS AND METHODS}

\section{Materials}

Globulaia alypum was collected from SETIF, Algeria in May 2010. All other reagents were purchased from Sigma Chemicals, Fluka (Germany) and Prolab (France).

\section{Extraction procedure}

The extractions were carried out using various polar and non-polar solvents. According to the method Markham (Markham, 1982), the powdered plant material (100 g) was extracted with methanol, at room temperature for overnight. The $\mathrm{MeOH}$ extracts were combined and concentrated under reduced pressure on a rotary evaporator. $\mathrm{MeOH}$ extract $(\mathrm{CrE})$ successively extracted with hexane, chloroform and ethyl acetate. Each fraction was evaporated at a temperature of $40^{\circ} \mathrm{C}$ to dryness under reduced pressure to give hexane ( $\mathrm{HE})$, chloroform $(\mathrm{ChE})$, ethyl acetate $(\mathrm{AcE})$, and the remaining aqueous $(\mathrm{AqE})$ extracts.

\section{Determination of total flavonoid contents}

The total flavonoid content of each extract was determined by a colorimetric method as described by Bahorun et al (1996). Each sample $(1 \mathrm{ml})$ was mixed with $1 \mathrm{ml}$ of aluminum chloride $\left(\mathrm{AlCl}_{3}\right)$ solution $(2 \%)$ and allowed to stand for $15 \mathrm{~min}$. Absorbance of the mixture was then determined at $430 \mathrm{~nm}$ versus prepared methanol blank. Results were expressed as equivalent quercetin and rutin (mg quercetin or rutin /g dried extract).

\section{Determination of Total polyphenols}

Total phenolic content was determined by the FolinCiocalteu method (Li et al., 2007). $200 \mu \mathrm{l}$ of diluted sample were added to $1 \mathrm{ml}$ of 1:10 diluted Folin-Ciocalteu reagent. After $4 \mathrm{~min}$, $800 \mathrm{ml}$ of saturated sodium carbonate solution $(75 \mathrm{~g} / \mathrm{l})$ was added. After incubation for $1 \mathrm{~h}$ at room temperature, the absorbance at 765 $\mathrm{nm}$ was measured in triplicate. Gallic acid $(0-160 \mu \mathrm{g} / \mathrm{ml})$ was used for calibration of standard curve. The results were expressed as microgram gallic acid equivalent (mg GAE) / mg of extract.

\section{Effect of extracts on XO}

Bacterial xanthine oxidase was puchased from sigma, the effect of extracts on xanthine oxidation was examined spectrophotometrically at $295 \mathrm{~nm}$ (UV-visible Technicomp 8500) following the production of uric acid using an absorption coefficient of $9600 \mathrm{M}^{-1} \mathrm{~cm}^{-1}$. Different concentrations of tested compounds were added to samples before the enzyme had been added and their effect on the generation of uric acid was used to calculate regression lines and $\mathrm{IC}_{50}$ values. The reaction was started by the addition of XO.

The enzyme activity of the control sample was set to $100 \%$ activity (Boumerfeg et al., 2009). The type of inhibition of different extracts was determined by the Lineweaver-Burk plot using varying concentrations of xanthine.

\section{Hypouricemic effects of extracts on potassium oxonate- induced hyperuricemia in mice}

Experiments were performed on adult male mice from the Pasteur Institute of Algeria weighing 25-30 g. They were kept under standardized conditions (temperature 21-24 ${ }^{\circ} \mathrm{C}$ and a light/dark cycle of 12 hours/12 hours) and fed a normal laboratory diet. After 1 week of acclimatization, mice's were divided into groups of 9-10 animals. Induction of hyperuricemia is made by injection intraperitoneally of $200 \mathrm{mg} / \mathrm{kg}$ of potassium oxonate, which is an uricase inhibitor (Osada et al., 1993). After 1 hour the extracts were administered intraperitoneally (100 mg/ kg). The mice are divided into 7 groups:

- Group 1 (Control): untreated or injected with the vehicle (normal saline), normal group.

- $\quad$ Group 2 (PO): injected with potassium oxonate.

- Group 3 (PO + allopurinol): the group injected with potassium oxonate then treated with $10 \mathrm{mg} / \mathrm{kg}$ of allopurinol.

- $\quad$ Group $4(\mathrm{PO}+\mathrm{CrE})$ : injected with potassium oxonate then treated with $100 \mathrm{mg} / \mathrm{kg}$ of CrE.

- $\quad$ Group $5(\mathrm{PO}+\mathrm{ChE})$ : injected with potassium oxonate then treated with $100 \mathrm{mg} / \mathrm{kg}$ on of ChE.

- Group $6(\mathrm{PO}+\mathrm{AcE})$ : injected with potassium oxonate then treated with $100 \mathrm{mg} / \mathrm{kg}$ of AcE.

- $\quad$ Group $7(\mathrm{PO}+\mathrm{AqE})$ : injected with potassium oxonate then treated with $100 \mathrm{mg} / \mathrm{kg}$ of AqE.

Whole blood samples were collected from anesthetized mice and centrifuged at $1500 \mathrm{~g}$ for 5 minutes. The serum obtained was stored at $-20{ }^{\circ} \mathrm{C}$ until use. Livers from each group were collected, rinsed with saline and homogenized in a phosphate buffer $(50 \mathrm{mM}, \mathrm{pH} 7.8)$ and centrifuged at $8000 \mathrm{~g}$ for $15 \mathrm{~min}$ at $4^{\circ} \mathrm{C}$. The supernatant is used for the determination of uric acid (Shi-Fu et al., 2007; Huang et al., 2011). The concentration of uric acid in the serum and supernatant of the liver is determined by an enzymatic method.

To evaluate the effect of the extracts on renal function, the levels of urea and creatinine was determined. These assays were carried out at the Central Laboratory of the University, Hospital of SETIF using a Bechman device and kits purchased from Cypress Diagnostics. 


\section{Statistical analysis}

All experiments were done in triplicate and results were reported as mean \pm SD. Data were analyzed by one way ANOVA. Statistically significant effects were further analyzed and means were compared using Tukey test. Statistical significance was determined at $\mathrm{p}<0.05$.

\section{RESULTS AND DISCUSSION}

\section{Total phenolic and flavonoid content}

In order to characterize the different extracts, a total dosage of flavonoids and polyphenols is performed. The assay method of total polyphenols is the Folin-Ciocalteau. Gallic acid was used as standard and total polyphenol content is expressed as micrograms of gallic acid equivalents per milligram of extract (EAG $\mu \mathrm{g} / \mathrm{mg}$ extract).

The dosage of flavonoids is formed according to the method of aluminum trichloride using as a standard the quercetin. The flavonoid content is expressed as micrograms of quercetin equivalents per milligram of extract (EQ $\mu \mathrm{g} / \mathrm{mg}$ extract). The results showed that the extract (AcE) is the richest in polyphenols and flavonoids followed by $\mathrm{CrE}$ and $\mathrm{AqE}$, whereas $\mathrm{ChE}$ is the poorest (Table 1).

Table 1: Determination of total polyphenols and flavonoids in the extract of GA.

\begin{tabular}{ccc}
\hline EA. & Polyphenols $^{\text {(a) }}$ & Flavonö̈ds $^{(\mathbf{b})}$ \\
\hline $\mathrm{CrE}$ & $140.24 \pm 4.18$ & $2.64 \pm 0.08$ \\
$\mathrm{ChE}$ & $81.01 \pm 1.91$ & $1.12 \pm 0.15$ \\
$\mathrm{AcE}$ & $157.74 \pm 5.27$ & $8.56 \pm 0.22$ \\
$\mathrm{AqE}$ & $100.86 \pm 0.76$ & $2.20 \pm 0.12$ \\
(b) $\mu \mathrm{g}$ of gallic acid equivalent per mg of extract & \\
(a) $\mu \mathrm{g}$ of quercetin equivalent per mg extract. & \\
Values represent the average of 3 to 4 measurements $\pm \mathrm{SD}$.
\end{tabular}

\section{Effect of extracts on XO}

The inhibitory activity of the extracts on the $\mathrm{XO}$ was evaluated spectrophotometrically by following the decrease of the production of uric acid at $295 \mathrm{~nm}$ (XO activity). The results obtained showed that the inhibition is dose-dependent (Figure.1).

The $\mathrm{AcE}$ has a very significant inhibitory effect $\left(\mathrm{IC}_{50}=\right.$ $0.069 \pm 0.003 \mathrm{mg} / \mathrm{ml})$ followed by $\mathrm{CrE}$ and $\mathrm{AqE}(0.081 \pm 0.000$ et $0.088 \pm 0.002 \mathrm{mg} / \mathrm{ml}$, respectively). $\mathrm{IC}_{50}$ values are 34,40 and 44 times higher comparing to allopurinol which is a specific inhibitor of XO, respectively for AcE, $\mathrm{CrE}$ and $\mathrm{AqE}$ (Table. 2).

A significant correlation $\left(\mathrm{R}^{2}=0.631\right)$ was observed between the polyphenol content and their inhibitory effect. The most important inhibitory effect EAc extract on the XO can be explained by the presence of relatively high in polyphenols and flavonoids rate.

To determine the relationship between the chemical structures of flavonoids and their inhibitory activity, we determined the type of inhibition for each extract. The results are shown in Table 2 and Figure 2. The $\mathrm{CrE}, \mathrm{ChE}$ and $\mathrm{AqE}$ inhibit competitively $\mathrm{XO}$, The same type of inhibition was found in the case allopurinol and quercetin (Figure 3). Whereas AcE is a non- competitive inhibitor. Inhibition of XO activity by the extracts resulted in the presence of one or more compounds acting independently or synergistically on the active sites of the enzyme.

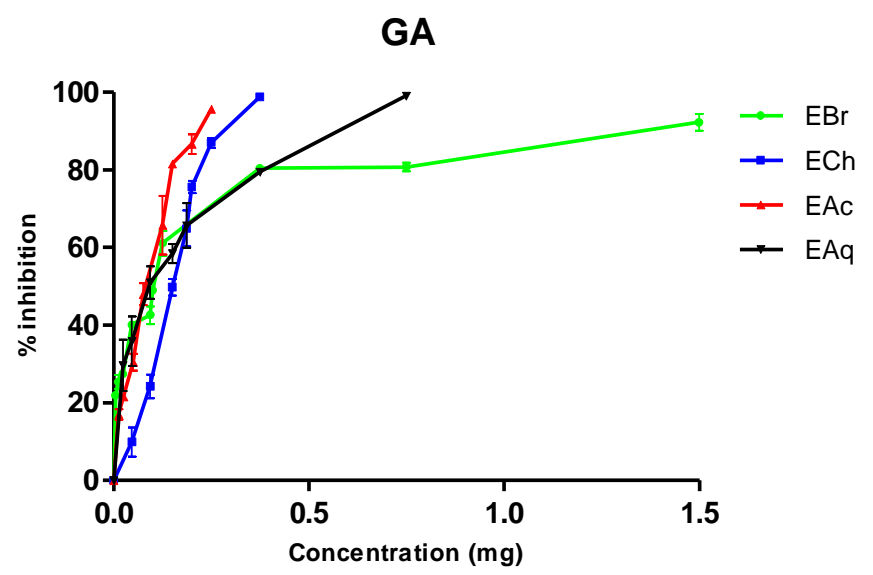

Fig. 1: Inhibition of XO by the extracts of $G A$.

Table 2: The determination of $\mathrm{IC}_{50}$ and the type of inhibition of extracts of $G A$.

\begin{tabular}{ccc}
\hline Extraits & $\mathbf{I C}_{\mathbf{5 0}}(\mathbf{m g} / \mathbf{m l})$ & Type of inhibition \\
\hline $\mathrm{CrE}$ & $0.088 \pm 0.000^{* * * *}$ & compétitif \\
$\mathrm{ChE}$ & $0.123 \pm 0.004^{* * *}$ & compétitif \\
$\mathrm{AcE}$ & $0.069 \pm 0.003^{* * *}$ & Non compétitif \\
AqE & $0.081 \pm 0.002^{* * *}$ & compétitif \\
Allopurinol & $0,002 \pm 0,00002$ & competitive \\
Quercetin & $\mathrm{Nd}$ & competitive \\
Catechin & $\mathrm{Nd}$ & uncompetitive \\
\hline
\end{tabular}

Values are an average of 3 to 4 trials \pm SD. Comparison was realized against allopurinol. $* * *: p \leq 0,001$, and ns: not significant.

Berboucha et al (2010) tested the XO inhibitory activity of a mixture of quercetin and catechin to determine the effect of simultaneous interaction of two potential inhibitors. The results showed that the type of inhibition is mixed, which means that the type of inhibition can be modified by the presence of other molecules present in the extract of plants by nonspecific interactions.

Cos et al. (1998) measured the activity of thirty flavonoids on uric acid production by XO. They have thus determined the relationship between the chemical structure of flavonoids and their inhibitory activity of this enzyme. The presence of the double bond between $\mathrm{C} 2$ and $\mathrm{C} 3$ carbons of the ring A flavonoid is very important for inhibition. This double bond and the conjugation it induces, causes the coplanarity of the ring $\mathrm{B}$ with the rings $\mathrm{A}$ and $\mathrm{C}$.

A flat structure is in fact necessary for high inhibitory activity against the XO (Van Hoorn et al., 2002). Finally, to get an overall view of the XO inhibitory activity of the extracts, an in vivo study is desirable on hyperuricemic models, starting from the fact that a substance can be active in vitro, can lose activity once penetrated into the body and vice versa. 




Lineweaver-Burk

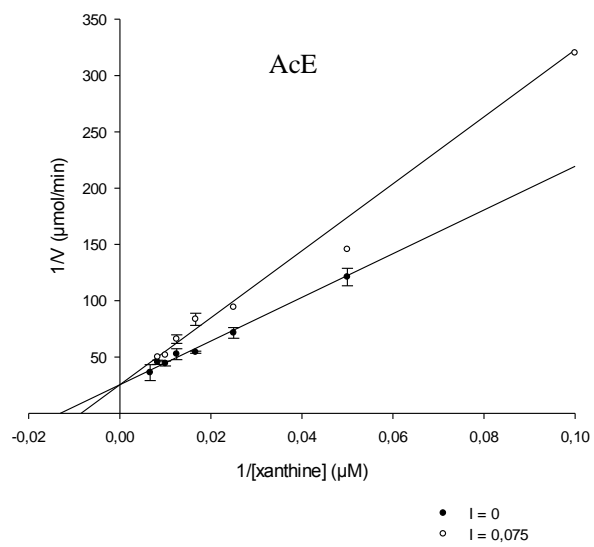

Lineweaver-Burk

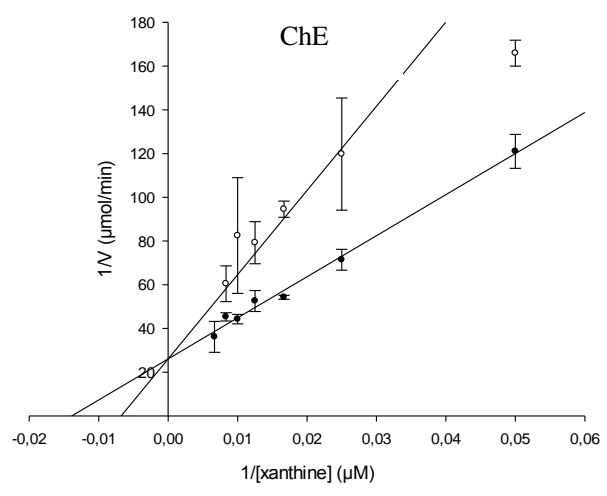

$-\quad I=0$
$\circ \quad I=0,15$

Lineweaver-Burk

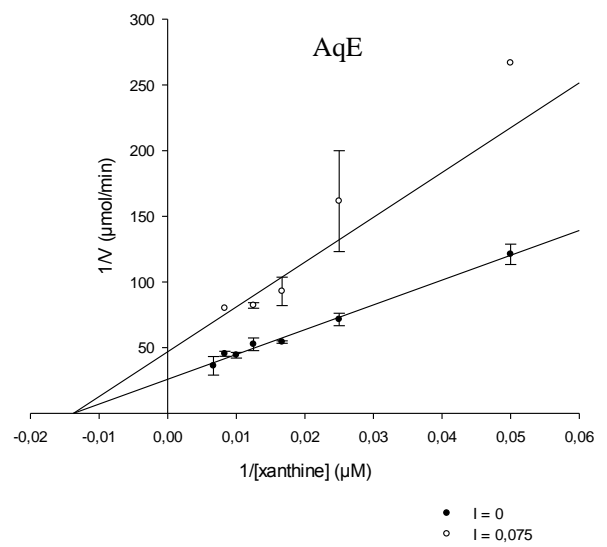

Fig. 2: Lineweaver-Burk plot of inhibition of $X O$ by extracts of GA. Values were expressed as mean $\pm S D(n=3$

Lineweaver-Burk

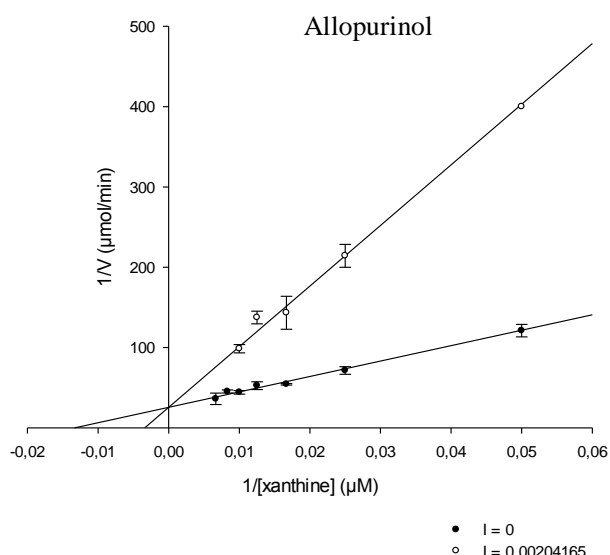

Lineweaver-Burk

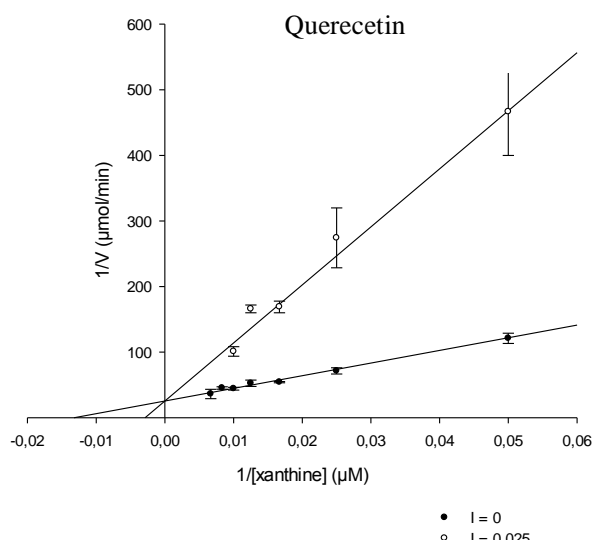

Fig. 3: Lineweaver-Burk plot of inhibition of XO by quercetin and allopurinol. Values are mean \pm SD $(n=3)$.

\section{Hypouricemic effects of extracts on potassium oxonate- induced hyperuricemia in mice}

Hyperuricemia is induced by intraperitoneally injection of potassium oxonate which is a competitive inhibitor of liver uricase, it partially blocks the conversion of uric acid to allantoin and therefore it increase the levels of uric acid in the mice serum giving an animal model hyperuremic (Osada et al., 1993; Huang et al., 2011). The uric acid, urea and creatinine were measured in serum and supernatant of liver.

We tried to verify the inhibitory effect of extracts of GA on the $\mathrm{XO}$ in vivo by measuring the uric acid level in serum and liver supernatant to confirm the in vitro inhibitory effect of the extracts and thus try to compare between the inhibitory effect in vitro and in vivo. 
Uric acid (serum)

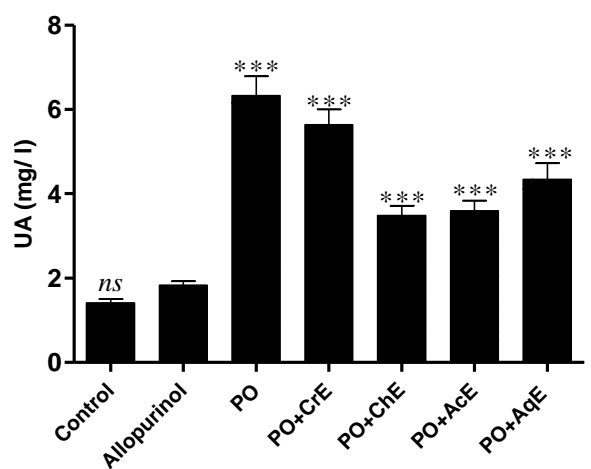

Uric acid (liver)

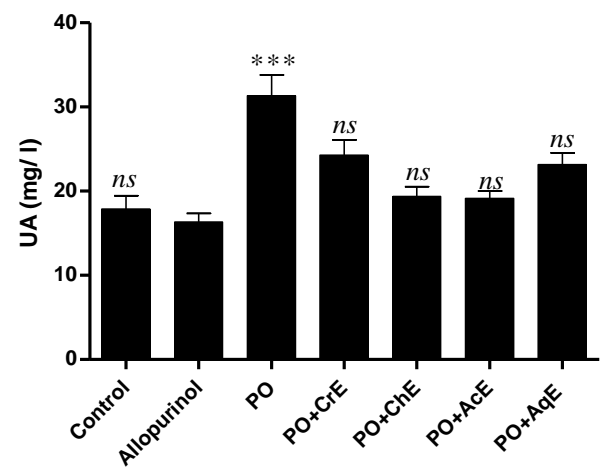

Fig. 4: Hypouricemic effects of extracts of GA. Comparison against the Allopurinol group, $* * * p \leq 0,001$, ns: not significant.

Urea (serum)

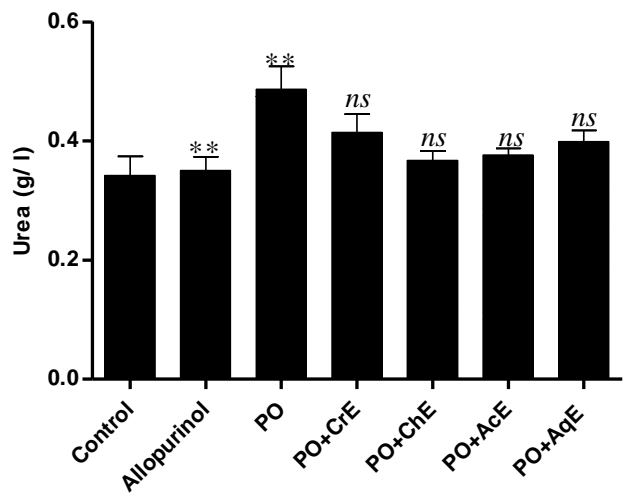

Creatinine (serum)

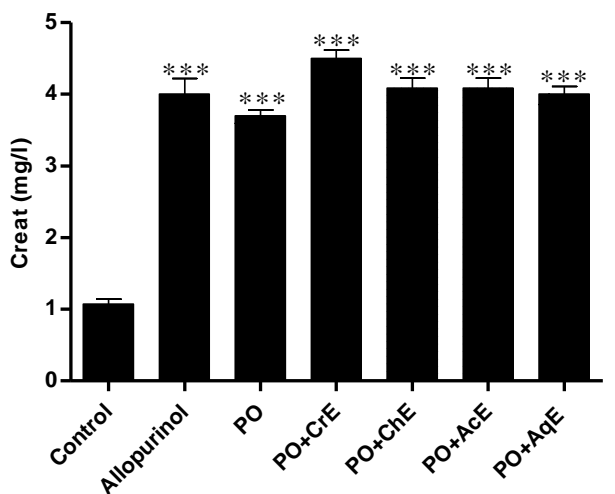

Fig. 5: Renal function evaluation by the determination of urea and creatinine. Comparison against the control group, ${ }^{* * *} \mathrm{p} \leq 0.001$, ns: not significant.

The value of uric acid in the control group: $1.48 \pm 0.07$ $\mathrm{mg} / \mathrm{l}$, for the "OP" group, the uric acid level is significantly increased: $6.33 \pm 0.46 \mathrm{mg} / \mathrm{l}$ two hours after the intraperitoneal injection of potassium oxonate indicating that it has successfully induced hyperuricemia (Figure 4).

The ChE, AcE, and AqE extracts have reduced significantly the plasma and liver uric acid levels (decreased 44.76\%, $43.03 \%$ and $31.31 \%$, respectively). The ChE and AcE caused a very remarkable effect comparing to the positive control "allopurinol" especially the liver uric acid (allopurinol $=16.36$ $\mathrm{mg} / \mathrm{l}, \mathrm{ChE}=19.4 \mathrm{mg} / \mathrm{l}$ and $\mathrm{AcE}=19.1 \mathrm{mg} / \mathrm{l})$. Comparing these results with those obtained in vitro, the $\mathrm{ChE}$ extract with the lowest inhibitory effect in vitro $\left(\mathrm{IC}_{50}=0.123 \mathrm{mg} / \mathrm{ml}\right)$ is the most effective effect in vivo. CrE reduced the uric acid levels but this reduction remains not significant $(5.64 \pm 0.36 \mathrm{mg} / \mathrm{l})$ compared to allopurinol group $(1.89 \pm 0.1 \mathrm{mg} / \mathrm{l})$. In contrast to in vitro results, the $\mathrm{CrE}$ has a remarkable inhibitory activity $\left(\mathrm{IC}_{50}=0.088 \mathrm{mg} / \mathrm{ml}\right)$. In summary, there is a big contradiction between inhibition in vitro and in vivo, this inconsistency or difference may be due to the difference in the bioavailability of flavonoids or natural substances and their extensive metabolism in mice (Huang et al., 2011).

\section{Renal fonction evaluation}

The objectives of this study is to evaluate the effect of the extracts on renal function. The rate of urea and creatinine levels can be indicators for the assessment of renal function. Kidney injury may be accompanied by an increase of creatinine and urea.

In hyperuricemic mice, Allopurinol (10 $\mathrm{mg} / \mathrm{kg})$ increased the rate of creatinine and the urea level comparing to normal control mice (Figure 5). Our results are in agreement with the results obtained by $\mathrm{Li}$ and al (2011), they showed that the induction of the hyperuricemia by potassium oxonate caused renal dysfunction and thus it increased the rate of uric acid and creatinine. All extracts and allopurinol did not decrease the rate of creatinine (Figure 5). However, the level of urea decreased compared to normal control mice. By comparing to the "PO" group $(0.48 \mathrm{~g} / \mathrm{l})$, only the $\mathrm{AcE}$ and $\mathrm{ChE}$ presented a protective effect by decreasing of urea levels.

\section{CONCLUSION}

The test for inhibition of $\mathrm{XO}$ activities revealed that the $\mathrm{AcE}$ is the most powerful extract. The $\mathrm{CrE}, \mathrm{ChE}$ and $\mathrm{AqE}$ exhibited and showed a competitive type of inhibition. Inhibition of XO activity by the extracts has resulted in the presence of one or more compounds acting independently or synergistically on the active sites of the enzyme. The in vitro inhibitory effect of this plant on the $\mathrm{XO}$ is confirmed in vivo on an animal model hyperurecimic. The extracts $\mathrm{ChE}$, AcE and $\mathrm{AqE}$ caused a 
significant decrease in plasma uric acid. The hypouricemic effect could be due to inhibition of XO by these extracts. Indeed, comparison of the inhibition of $\mathrm{XO}$ in vivo and in vitro, according to a "contradiction"; the extracts are not effective in vitro, are highly effective in vivo, and vice versa. These results remain preliminary, it would be interesting to test the activity of fractions and molecules that underlie the various activities detected in the different extracts. In addition, extensive further studies concerning the identification of phenolic compounds by more efficient methods are needed and a toxicological study is very requested.

\section{ACKNOWLEDGMENTS}

This work was supported by the Algerian Ministry of Higher Education and Scientific Research (MERS) and by the Algerian Agency for the Development of Research in Health (ANDRS).

\section{REFERENCES}

Ramesh CK, Rehman A, Prabhakar BT, Vijay Avin BR, Aditya Rao SJ. Antioxidant potential in sprouts vs. seeds of Vigna radiata and Macrotyloma uniflorum. J App Pharm Sci, 2011; 1:99-103.

Sachs L, Batra KL, Zimmermann B. Medical implications of hyperuricemia. Medicine and Health, 2009; 92: 353-355.

Unno T, Sugimoto A, Kakuda T. Xanthine oxidase inhibitors from the leaves of Lagerstroemia speciosa (L). Pers. J. Ethnopharmacol, 2004; 93: 391-395.

Newcombe DS. 2013. Clinical Aspects of Gout and Associated Disease States. Chapitre 5. In: Gout: Basic Science and Clinical Practice. London. Springer-Verlag. p. 91-159.

Hille R. 2010. Epr studies of xanthine oxidoreductase and othermolybdenum-containing hydroxylases. In: Metals in Biology: Applications of High-Resolution EPR. London. Springer Science and Business Media. p. 92-120.

Chen P, Hung SI, Chen SY, Chen YT. 2011. Allopurinol. Chapter 13. In: Pharmacogenomic Testing in Current Clinical Practice, Molecular and Translational Medicine. London. Springer Science+ Business Media. p. 213-222.

Bomalaski JS., Clark MA. Serum uric acid-lowering therapies: where are we heading in management of hyperuricemia and the potential role of uricase. Current Rheumatoolgyl Rep, 2004; 6:240-247.

Yu Z, Fong WP, Cheng HK. The dual actions of morin (3,5,7,2,4- pentahydroxyflavone) as a hypouricemic agent: uricosuric effect and xanthine oxidase inhibitory activity. The journal of pharmacology and experimental therapeutics, 2006; 316(1) : 169-175.

Lin CM, Chen CS, Chen CT, Liang YC, Lin JK. Molecular modeling of flavonoids that inhibits xanthine oxidase. Biochem. Biophys. Res. Commun, 2002; 294:167-172.

Fehri, B., Aiache, J.M. Effects of Globularia alypum L. on the gastrointestinal tract. Journal of Natural Product, 2010; 3: 141-146.
Balansard, J, Delphant J. La globulaire: un purgatif oublié. Revue de Phytothérapie, 1948; 12:213-234.

Skim F, Kaaya A, Jaouhari JT, Lazrek HB, Jana M, El Amri H. Hypoglycaemic activity of Globularia alypum leaves in rats. Fitoterapia, 1999; 70: 382-389.

Jouad H, Maghrani M, Eddouks M. Hypoglycaemic effect of Rubus fructicosis L. and Globularia alypum L. in normal and streptozotocin-induced diabetic rats. Journal of Ethnopharmacology, 2002 81: $351-356$

Markham KR. 1982. Techniques of flavonoid identification. Academic press, London, Chap. 1 and 2, 1-113.

Bahorun T, Gressier B, Trotin F, Brunete C, Dine T, Vasseur J, Gazin JC, Pinkas M, Luycky M, Gazin M. Oxigen species scavenging activity of phenolic extract from howthorn fresh plant organs and pharmaceutical preparation. Arzneim Forsch / Drug Research, 1996; 1-6.

Li HB., Cheng KW., Wong CC., Fan KW., Chen F., Jiang Y. Evaluation of antioxidant capacity and total phenolic content of different fractions of selected microalgae. Food chemistry, 2007; 102: 771-776.

Boumerfeg S, Baghiani A, Messaoudi D, Khennouf S, Arrar L . Antioxidant Properties and Xanthine Oxidase Inhibitory Effects of Tamus communis L. Root Extracts. Phytotherapy Research, 2009; 23: 283-288.

Osada Y, Tsuchimoto M, Fukushima H, Takahashi K, Kondo S, Hasegawa M, and Komoriya K. Hypouricemic effect of the novel xanthine oxidase inhibitor, TEI-6720, in rodents. Eur J Pharmacol, 1993; 241: 183 188. Abstract.

Shi-Fu M, Feng Z, Yao-Zhong LV, Qing-Hua H, Dong-Mei Z, Ling-Dong K. Hypouricemic Action of Selected Flavonoids in Mice: Structure-Activity Relationships. Biology Pharmacology Bulletin, 2007; 30(8): 1551-1556.

Huang J, Wang S, Zhu M, Chen J, Zhu X. Effects of Genistein, Apigenin, Quercetin, Rutin and Astilbin on serum uric acid levels and xanthine oxidase activities in normal and hyperuricemic mice. Food and Chemical Toxicology, 2011; $49: 1943-1947$.

Berboucha M, Ayouni K, Atmani D, Atmani Dj, Benboubetra M. Kinetic Study on the Inhibition of Xanthine Oxidase by Extracts from Two Selected Algerian Plants Traditionally Used for the Treatment of Inflammatory Diseases. Journal of medicinal food, 2010; 13 (4): 1-9.

Cos P, Ying L, Calomme M, Hu JP, Cimanga K., Van Poel B., Pieters L., Vlietinck A., Vanden Berghe D. Structure-activity relationship and classification of flavonoids as inhibitors of xanthine oxidase and superoxide scavengers. Journal of natural product, 1998; 61, 71-76.

Van Hoorn DEC., Nijveldt RJ., Van Leeuwen PAM., Hofman Z., M'Rabet L., De Bont DBA. Van Norren K. Accurate prediction of xanthine oxidase inhibition based on the structure of flavonoids. European Journal of Pharmacology, 2002; 451: 111-118

\section{How to cite this article:}

Naouel B, Hayat T, Iman K, Lekhmissi A, Abderrahmane B. Kinetics of Inhibition of Xanthine Oxidase by Globularia alypum and its Protective Effect against Oxonate- Induced Hyperuricemia and Renal Dysfunction in Mice. J App Pharm Sci, 2016; 6 (04): $159-164$ 